\title{
Symbiosis volumes one (1985) to 39 (2005) now available on-line
}

\author{
D. H. S. Richardson ${ }^{1}$
}

Published online: 18 May 2020

(C) Springer Nature B.V. 2020

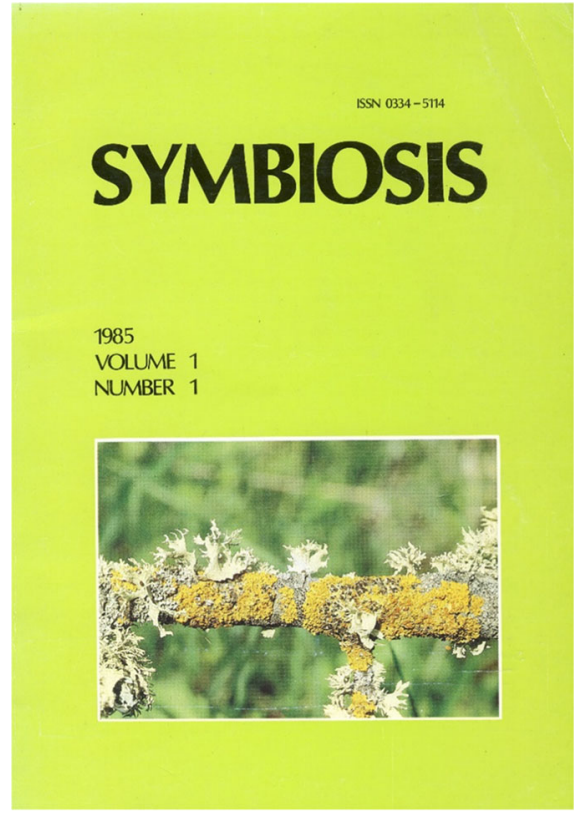

Professor Margalith Galun founded the journal Symbiosis in 1985 to provide, for the first time, a single place, where research papers and reviews on symbiotic associations could be consulted (Galun 2011). Soon afterwards she realized that a venue for interpersonal interaction was needed and organized the first International Symbiosis Congress. These early issues of Symbiosis include papers on a very wide range of symbiotic associations. At the second ISS Congress, the associated International Symbiosis Society was established. The journal, from its inception, was published in hard copy by Balaban Publishers in Israel and then it was transferred to Springer in the Netherlands. Currently, nine issues per year (comprising three volumes) are produced by Springer and available both on-line and in hard copy.

D. H. S. Richardson

david.richardson@smu.ca

1 Environmental Science, Saint Mary's University, 923 Robie Street, Halifax, Nova Scotia B3H 3C3, Canada
Until now, the early issues of Symbiosis were only available in hard copy and have not been available on-line. However, following the transfer of copyright by Miriam Balaban to the International Symbiosis Society, it has proved possible with finances from the ISS to scan, and make searchable, the entire run of Symbiosis published by Balaban. This was done using the nearly complete run of Symbiosis that belonged to David Richardson and then donated to Saint Mary's University. Just three issues were missing. By contacting those who had been early members of the Symbiosis Editorial Board, the three issues were tracked down and scanned with the help of Professor Paola Bonfante in Italy. The remaining 43 volumes were digitized by Precision Digital Imaging Services in Halifax. Upon completion, the files were transferred to Dalhousie University for long term digital preservation and access. To date, the issues of Symbiosis from 1985 until 2005 have been put up on DalSpace and can be accessed free on-line via Dalhousie's institutional repository. The remaining issues, years 2006-2008 are awaiting transfer to DalSpace, but the process is delayed due to the University being shut for the rest of the semester as a result of the COVID-19 virus pandemic. The URL for the collection is dalspace.library.dal.ca/handle/10222/76841

Acknowledgements I would like to thank Miriam Balaban of Balaban Publishers for transferring the copyright to the International Symbiosis Society and providing encouragement, and the International Symbiosis Society for providing funds to scan the issues, Kurtis Macewen, Precision Digital Imaging Services Inc., Halifax, for overseeing the scanning and providing very helpful advice, and Ann Barrett and Geoff Brown, Dalhousie University Libraries for facilitating transfer of the data onto DalSpace.

Galun M (2011) The symbiosis community: how the journal, the conference and the society began. Symbiosis 53:47-48

Publisher's note Springer Nature remains neutral with regard to jurisdictional claims in published maps and institutional affiliations. 